\title{
Calibration of amplification factors using KiK-net strong-motion records: toward site effective estimation of seismic intensities
}

\author{
Takumi Hayashida and Fumiko Tajima \\ Department of Earth and Planetary Systems Science, Graduate School of Science, Hiroshima University, \\ 1-3-1 Kagami-yama, Higashi-Hiroshima 739-8526, Japan
}

(Received April 16, 2007; Revised August 21, 2007; Accepted September 10, 2007; Online published October 19, 2007)

\begin{abstract}
Estimated seismic intensities using conventional relationships are not always in agreement with those observed at specific sites. We investigate subsurface amplification factors using the KiK-net strong-motion data recorded both in the borehole and on the ground surface and attempt to estimate more accurate intensities at a given site. Here the amplification factors are evaluated using the ratios of peak velocity amplitudes $V_{\text {surf }} / V_{\text {bor }}$ that are calculated from records on the ground surface and in the borehole. The ratios (amplification factors) decrease with hypocentral distance in general, but the attenuation characteristics vary from station to station. At stations where large amplifications are observed, the ratios show large scatter relative to the empirical amplification formulas. The variation is also affected by the incident direction of seismic waves as well as the hypocentral distance. We derived empirical amplification formulas of $V_{\text {surf }} / V_{\text {bed }}$ where $V_{\text {bed }}$ is the peak velocity on the engineering bedrock as a function of hypocentral distance at individual stations (i.e. specific sites) in place of the conventionally used amplification constants. The estimated intensities using the site-effective formulas show substantial improvement at most of the stations in comparison with those calculated using conventional formulas.
\end{abstract}

Key words: KiK-net, local site effect, attenuation relationship, seismic intensity.

\section{Introduction}

Ground motions are sometimes greatly amplified due to the response of the subsurface ground structure (i.e. local site effects), and it is important to understand the subsurface structure in strong motion estimation. The major amplifications result from the response of sediments in the subsurface structures which are heterogeneous and vary in threedimensional (3D) directions. It is straightforward to investigate the subsurface amplification by comparing seismograms observed in the borehole with those on the ground surface. The comparison of the sets of seismographs enables us to quantitatively evaluate local structural effects at a given site.

In Japan, the National Research Institute for Earth Science and Disaster Prevention (NIED) deploys a nationwide network of strong-motion seismographs that is called the KiK-net (KIBAN Kyoshin network, Japan; Aoi et al., 2000). At a KiK-net station, a set of three-component, strong-motion seismographs are located both on the ground surface and in the borehole. A Hi-net (High-Sensitivity Seismograph Network Japan; Obara, 2002) station is colocated with a KiK-net station in the borehole (Fig. 1). The Real-time Earthquake Information System (REIS) has been developed by NIED and is operational at present (Horiuchi et al., 2005; Yamamoto et al., 2005). Figure 1 illustrates the REIS configuration. The REIS utilizes data from the Hi-net in real-time. The Hi-net stations are equipped with sensors

Copyright (c) The Society of Geomagnetism and Earth, Planetary and Space Sciences (SGEPSS); The Seismological Society of Japan; The Volcanological Society of Japan; The Geodetic Society of Japan; The Japanese Society for Planetary Sciences; TERRAPUB with a high ability to detect seismic signals and excellent $\mathrm{S} / \mathrm{N}$. The REIS detects an event and determines earthquake parameters such as hypocenter, magnitude and origin time within $5 \mathrm{sec}$ automatically after the sensors detect $P$-waves. The broadcasting system monitors the shared memory and transmits the obtained earthquake parameters to the Earthquake Research Institute (ERI), University of Tokyo. Upon detection of a new event, the receiving system at remote sites displays earthquake parameters with an alarm of earthquake warning (Yamamoto et al, 2005). The system also predicts the arrival time and seismic intensity at a given site (i.e. station) in a timely fashion based on the intensity magnitude derived using data of the Hi-net (Yamamoto and Horiuchi, 2005). Here, the attenuation is assumed to follow a simple function of distance. However, as the Hi-net stations are located in the borehole, the estimated intensities (on the ground surface) using the borehole station data are not always in agreement with the observed ones on the ground surface.

We have investigated amplification factors observed at the KiK-net stations in Hiroshima prefecture to calibrate site amplification factors between the borehole and the ground surface. We then estimated seismic intensities using the derived empirical formula of attenuation and compared them with the observed ones on the ground surface.

\section{Methods and Data}

\subsection{KiK-net data}

The KiK-net is a network of strong motion instruments that consists of about 700 stations with an average spacing of about $20 \mathrm{~km}$ distributed throughout the Japan is- 
Table 1. List of the KiK-net stations and the number of data used in this study.

\begin{tabular}{|c|c|c|c|c|c|}
\hline Station code & Station name & $\begin{array}{l}\text { Depth to the } \\
\text { borehole* (m) }\end{array}$ & Geology* & $\begin{array}{l}V_{S 30} * * \\
(\mathrm{~m} / \mathrm{sec})\end{array}$ & $\begin{array}{l}\text { The number } \\
\text { of data points }\end{array}$ \\
\hline HRSH01 & MIHARA & 205 & Biotite granite & 405 & 98 \\
\hline HRSH02 & DAIWA & 100 & Biotite granite & 390 & 81 \\
\hline HRSH03 & MITSUGI & 200 & Biotite granite & 484 & 86 \\
\hline HRSH04 & NUMAKUMA & 200 & Clay slate & 448 & 17 \\
\hline HRSH05 & KANNABE & 200 & Diabase & 370 & 57 \\
\hline HRSH06 & KUCHIWA & 100 & Mudstone, Conglomerate & 280 & 100 \\
\hline HRSH07 & KURE & 102 & Granite & 462 & 98 \\
\hline HRSH08 & SAIKI & 100 & Mudstone, Biotite granite & 769 & 46 \\
\hline HRSH09 & KISA & 115 & Andesite & 492 & 54 \\
\hline HRSH10 & GEIHOKU & 100 & Rhyolite & 263 & 83 \\
\hline HRSH11 & JINSEKI & 100 & Sandstone & 698 & 34 \\
\hline HRSH12 & HIROSHIMA & 150 & Granite & 1071 & 24 \\
\hline HRSH13 & HIROSHIMAMINAMI & 200 & Granite & 405 & 33 \\
\hline HRSH14 & OKIMI & 100 & Granite & 536 & 30 \\
\hline HRSH15 & KURAHASHI & 100 & Granite & 588 & 41 \\
\hline HRSH16 & YOSHIDA & 100 & Granite & 455 & 42 \\
\hline HRSH17 & TOGOUCHI & 102 & Granite & 1111 & 13 \\
\hline HRSH18 & HIGASHI-HIROSHIMA & 100 & Granite & 400 & 34 \\
\hline
\end{tabular}

*After the KiK-net web site (http://www.kik.bosai.go.jo/kik/).

**Calculated using the PS log data of the individual stations.

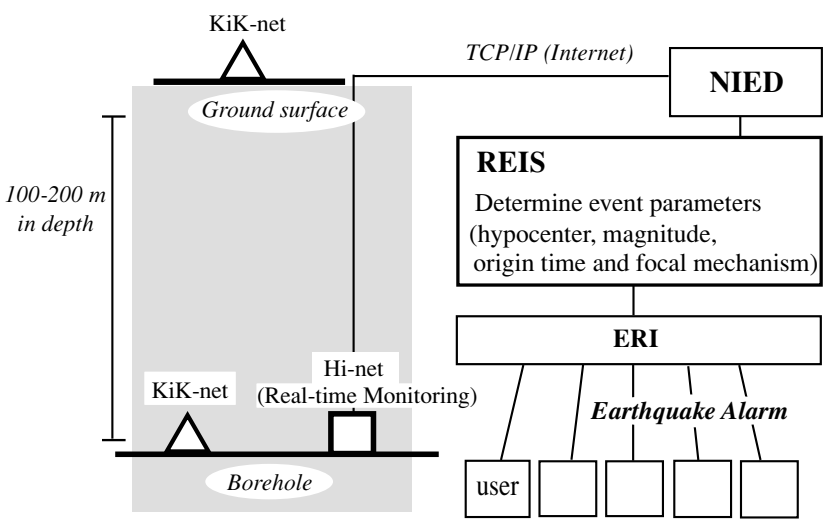

Fig. 1. Outline of a KiK-net station co-located with a Hi-net station in the borehole. The Hi-net station is monitored by the real-time earthquake information system (REIS) developed by NIED.

lands. The KiK-net stations are generally located at hard rock sites. Each station has two sets of three-component accelerometers, with one set installed on the ground surface and the other one in the borehole, which has a depth of $100 \mathrm{~m}$ or more to reduce various site effects and artificial noise. Figure 2 shows $18 \mathrm{KiK}$-net station locations in Hiroshima prefecture. The depths of the borehole at the stations in this region range between 100 and $205 \mathrm{~m}$ (see Table 1). The number of KiK-net stations increased progressively since the beginning of operation in 1997, and there are 18 stations in this prefecture at present. The KiK-net data are collected through dial-up operations by the Data Center of NIED and can be obtained through the web site (http://www.kiknet.bosai.go.jp/).

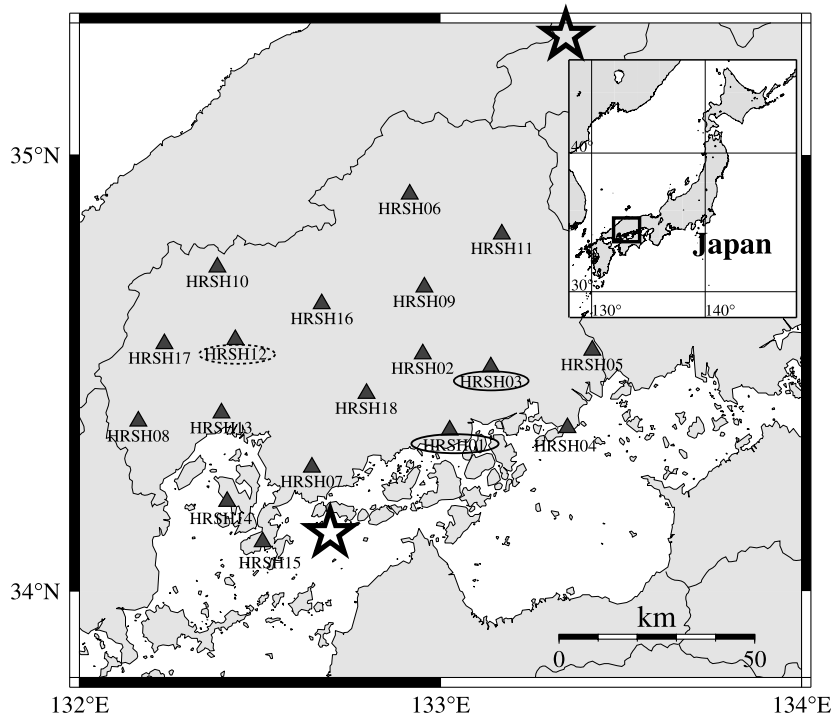

Fig. 2. Eighteen KiK-net station locations (denoted with station codes) in Hiroshima prefecture. Stations HRSH01 and HRSH03 show large amplification of ground motions on the ground surface, while other stations, such as HRSH12, do not. Stations HRSH01 and HRSH03 also show large variance of amplification from a standard line as a function of distance.

There are records for 237 events recorded by the 18 stations during the operation period (as of December 2006) in Hiroshima prefecture. We selected events recorded with a maximum acceleration of 2 gal or greater on the ground surface at least at one station from May 1998 to December 2006. A total of 191 events were selected, and their locations are plotted in Fig. 3. The hypocenters are located in a 


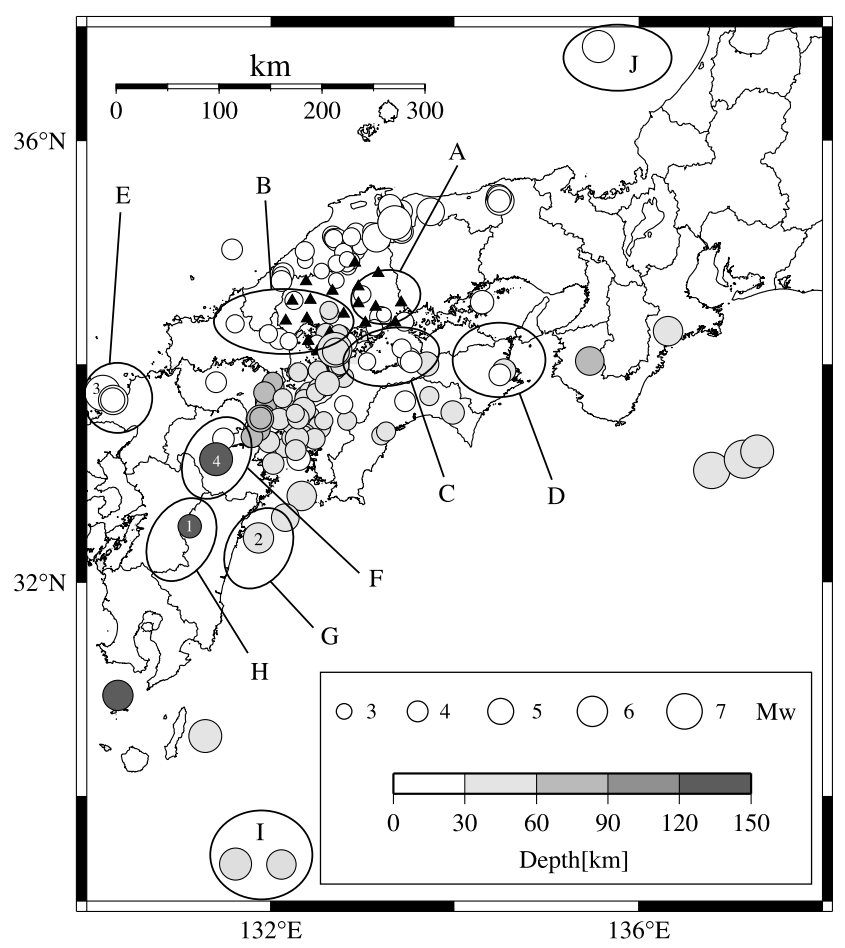

Fig. 3. Epicenters of 191 events (shown with circles) used in this study. The size of a circle corresponds to $M_{\mathrm{j}}$ and the shade corresponds to the depth of each event. Events 1 to 4 are discussed in some detail in the text. The solid triangles are the locations of KiK-net stations in Hiroshima prefecture (same as in Fig. 2). The source regions A to J, which show characteristic amplification at stations HRSH01 and HRSH03, are denoted by ellipses.

broad region in terms of station distance (from 4 to $602 \mathrm{~km}$ ), azimuthal coverage and source depths (from 6 to $147 \mathrm{~km}$ ), which characterize the sampling of seismic waves of the 3D structure. The range of the magnitude of the selected events is between 3.0 and 7.4 .

\subsection{Attenuation relationship}

At present, various empirical relationships of attenuation are widely used to estimate peak amplitudes for ground motions (e.g., Fukushima and Tanaka, 1990; Si and Midorikawa, 1999), response spectra (e.g., Takahashi et al., 2004; Kanno et al., 2006) and seismic intensities (Matsusaki et al., 2006), which are derived empirically based on felt-earthquake recordings. In this study we use the attenuation relationship of Midorikawa and Ohtake (2003), which was expanded from that of Si and Midorikawa (1999) to estimate peak ground velocity (PGV, $\left.V_{\text {surf }}\right)$. The peak velocities on the engineering bedrock $V_{\text {bed }}(\mathrm{cm} / \mathrm{s})$ are estimated according to the source depth range of the hypocenter $D$ $(\mathrm{km})$ as follows:

$$
\begin{gathered}
\log V_{\text {bed }}=b-\log (X+C)-k X, \\
\text { for } D \leq 30 \mathrm{~km}
\end{gathered}
$$

$\log V_{\text {bed }}=b+0.6 \log (1.7 D+C)-1.6 \log (X+C)-k X$,

$$
\text { for } D>30 \mathrm{~km}
$$

where $X$ is the shortest distance $(\mathrm{km})$ between the fault and the reference site and $k$ is a constant (0.002). The engineering bedrock depth is defined as the depth where the $S$-wave velocity $V_{s}$ is $600 \mathrm{~m} / \mathrm{s}$. Parameters $b$ and $C$ are derived using a regression analysis as

$$
b=a M_{\mathrm{W}}+h D+d_{i} S_{i}+e
$$

and

$$
C=0.0028 \times 10^{0.5 M_{\mathrm{w}}} .
$$

In the dataset used by Midorikawa and Ohtake (2003) $a$ is $0.65, h$ is $0.0024, d_{i}$ is the fault-dependent parameter $(0.00$ for crustal events, 0.05 for inter-plate events and 0.15 for intra-plate events) and $e$ is -1.77 . The moment magnitudes $\left(M_{\mathrm{W}}\right.$ 's $)$ which we use in this study are automatically determined by NIED. However, for events with $M_{\mathrm{j}}$ of less than $3.5, M_{\mathrm{W}}$ 's are not determined automatically (Fukuyama $e t$ al., 1998). In such cases, $M_{\mathrm{W}}$ is estimated using a simple empirical relationship between $M_{0}($ dyne $\cdot \mathrm{cm})$ and $M_{\mathrm{j}}$ (Takemura, 1990)

$$
\log M_{0}=1.17 M_{\mathrm{j}}+10.72
$$

and the relationship between $M_{0}$ and $M_{\mathrm{W}}$ (Kanamori, 1977; Hanks and Kanamori, 1979)

$$
\log M_{0}=1.5 M_{\mathrm{W}}+9.1 \text {. }
$$

Using Eqs. (5) and (6), the following relationship

$$
M_{\mathrm{W}}=0.78 M_{\mathrm{j}}+1.08
$$

is derived for shallow crustal events. For small events which are not crustal events, we assume that an $M_{\mathrm{j}}$ is equal to an $M_{\mathrm{W}}$. $V_{\text {surf }}$ 's are estimated by multiplying the peak velocity on the engineering bedrock by an amplification coefficient $R$ (Midorikawa et al., 1994) following:

$$
\begin{gathered}
\log R=1.83-0.66 \log V_{S 30}, \\
V_{\text {surf }}=R \times V_{\text {bed }},
\end{gathered}
$$

where $V_{S 30}(\mathrm{~m} / \mathrm{s})$ is the averaged $S$-wave velocities in the upper $30 \mathrm{~m}$.

\section{Local Site Effects Observed in KiK-net Strong- motion Records}

3.1 Comparison of amplitudes on the surface with those in the borehole

Figure 4 shows examples of two sets of raw ground acceleration seismograms recorded on the ground surface and in the borehole at the KiK-net stations HRSH03 and HRSH12 for the 2001 Geiyo earthquake. The upper three traces are the three components of accelerograms in the borehole, and the lower three are the data recorded on the ground surface. Since the horizontal components of borehole seismometers are not always aligned in the right direction (Shiomi et al., 2003), we have corrected them according to the instruction on the NIED web site. The peak ground accelerations (PGA's, $\mathrm{cm} / \mathrm{s}^{2}$ ) are indicated above the seismograms. The epicentral distances of these stations (i.e., 59 and $57 \mathrm{~km}$, respectively) and the maximum amplitudes in the borehole are close to each other at these stations. However, at HRSH03, the PGA's on the ground surface are 7.9to 14.3-fold larger than those in the boreholes, while the 

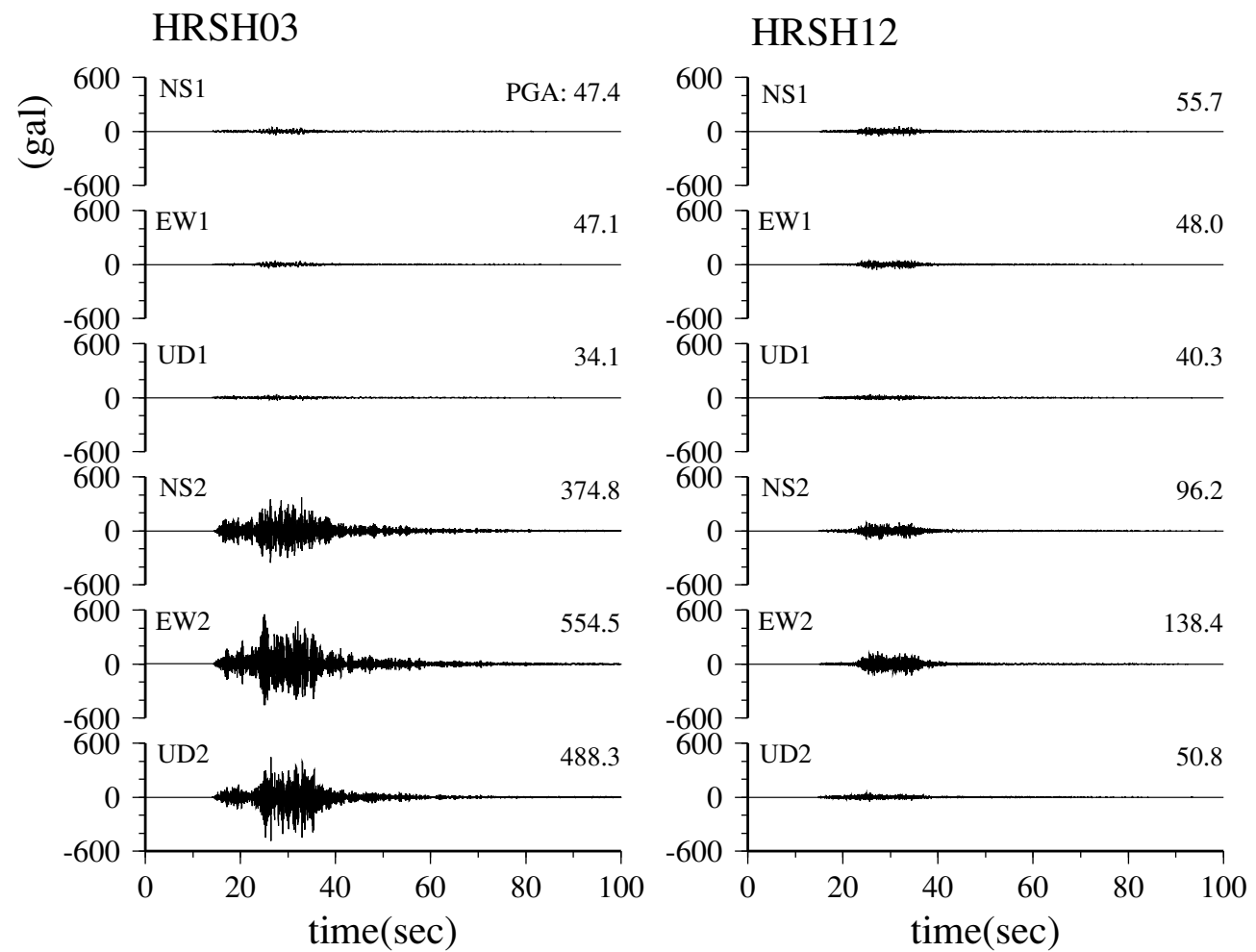

Fig. 4. Ground acceleration seismograms at the KiK-net stations: HRSH03 (left) and HRSH12 (right) during the 2001 Geiyo earthquake. The upper three traces are three-component (NS, EW, UD) accelerograms in the borehole, and the lower three traces are on the ground surface. The maximum amplitudes on the surface are 7.9- to 14.3-fold larger than those in the borehole at HRSH03, while the amplitudes on the ground surface are 1.3- to 2.2-fold larger than those in the borehole at HRSH12 (see the station locations in Fig. 2).

PGA's on the ground surface are just 1.3- to 2.2-fold larger than those in the borehole at HRSH12. The measured seismic intensities on the Japanese scale (JMA, 1996) at both of the borehole stations are 4. However, the intensities measured on the ground surface at HRSH03 and HRSH12 are 6- and 4, respectively. The observed intensity at HRSH03 exceeded the intensity estimated (e.g. 4) by the conventional method. At HRSH03, the ground surface amplification is generally large for other events.

\subsection{Amplification variation due to hypocentral dis- tances}

As mentioned above, the large amplification results in a larger seismic intensity on the ground surface than in the borehole. Such an amplification is observed at several KiKnet stations in Hiroshima prefecture. This large amplification on the ground surface could cause serious damage in a case of a large event if the frequency band of the amplified seismic waves coincides with the peak response spectra of buildings. Thus, it is important to evaluate amplification factors at individual sites. We define the amplification factor as a ratio of $V_{\text {surf }} / V_{\text {bor }}$ ( $V_{\text {bor }}$ is the peak velocity in the borehole measured from recordings at each of the KiK-net stations). The peak velocities are determined from the velocity waveforms which were integrated from the acceleration records and bandpass filtered between 0.1 and $10 \mathrm{~Hz}$. The ratios of $V_{\text {surf }} / V_{\text {bor }}$ at $18 \mathrm{KiK}$-net stations in Hiroshima prefecture are plotted in Fig. 5 as a function of hypocentral distance. We can clearly see that the ratios of $V_{\text {surf }} / V_{\text {bor }}$ tend to decrease with the hypocentral distance. At station HRSH03, the ratios of $V_{\text {surf }} / V_{\text {bor }}$ are large $(>10)$ in general, including one event that exceeded 50 for the hypocentral distances within $100 \mathrm{~km}$. In comparison, the ratios are small $(<5)$ at stations HRSH04, HRSH08, HRSH09, HRSH12, HRSH14 and HRSH17. The ratios also show large variance among the stations.

\subsection{Geological conditions}

Hiroshima prefecture is located in the Chugoku mountainous region on the north side and faces the Seto Inland Sea to the south. Thus, this prefecture includes mountains, plateaus and plain areas from north to south. The rock fabrics are generally granite and weathering granite. In the northern mountainous region, volcanic sandy soils, organic soils and erosional sandy soils are mainly deposited over the bedrock at an average depth of $200 \mathrm{~m}$. On the other hand, alluvial soils consisting of sand, gravels and silt are observed in the southern basin area. In the Chugoku region (including Hiroshima prefecture), the depth to the bedrock is shallower than other parts of Japan. The PS log data of the individual KiK-net stations are available from the NIED web site.

To evaluate seismic wave amplification caused by the subsurface structure, we calculated the ratios of velocity spectra on the ground surface to those in the borehole. Using these ratios, the structural effect deeper than the borehole station can be canceled to examine transfer functions between the borehole and the ground surface (Note the transfer functions include down-going waves from the surface, therefore, the functions do not equal the site effects). We calculate the spectral ratios of the coda portion $(10.24 \mathrm{sec})$ of $10 \mathrm{sec}$ after the $S$-wave arrivals both for hor- 

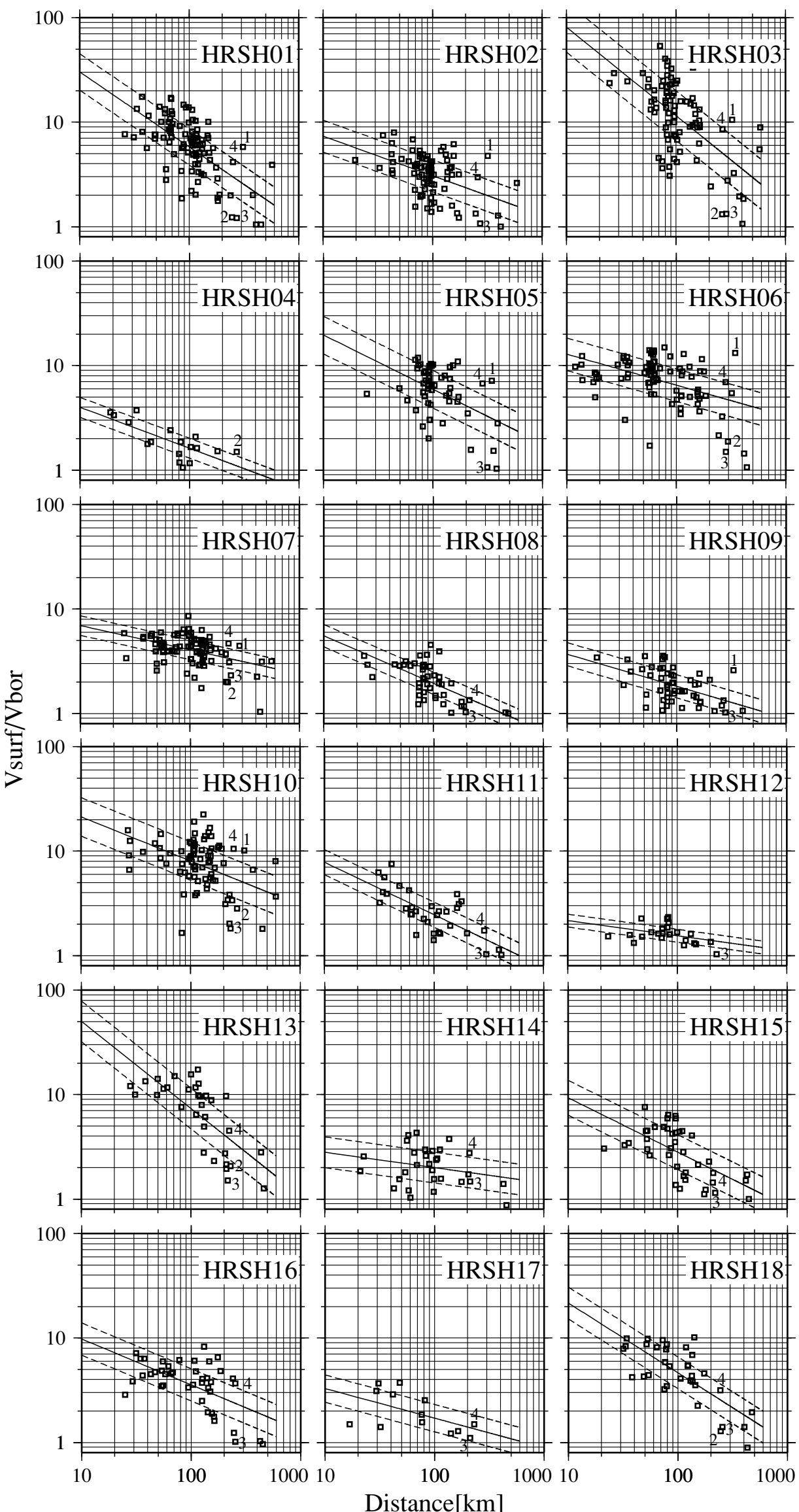

Distance $[\mathrm{km}]$

Fig. 5. Ratios of the peak velocity amplitudes on the ground surface to those in the borehole $\left(V_{\text {surf }} / V_{\text {bor }}\right)$ at KiK-net stations in Hiroshima prefecture as a function of hypocentral distance. Here the bandpass filter $(0.1-10 \mathrm{~Hz})$ was applied for the velocity data. The lines fitted by regression analysis (solid lines) and standard deviations $\pm \sigma_{1}$ (dashed lines) are also plotted for each station. The numbers (1-4) indicate events which show characteristic amplifications (details are stated in the main text). 

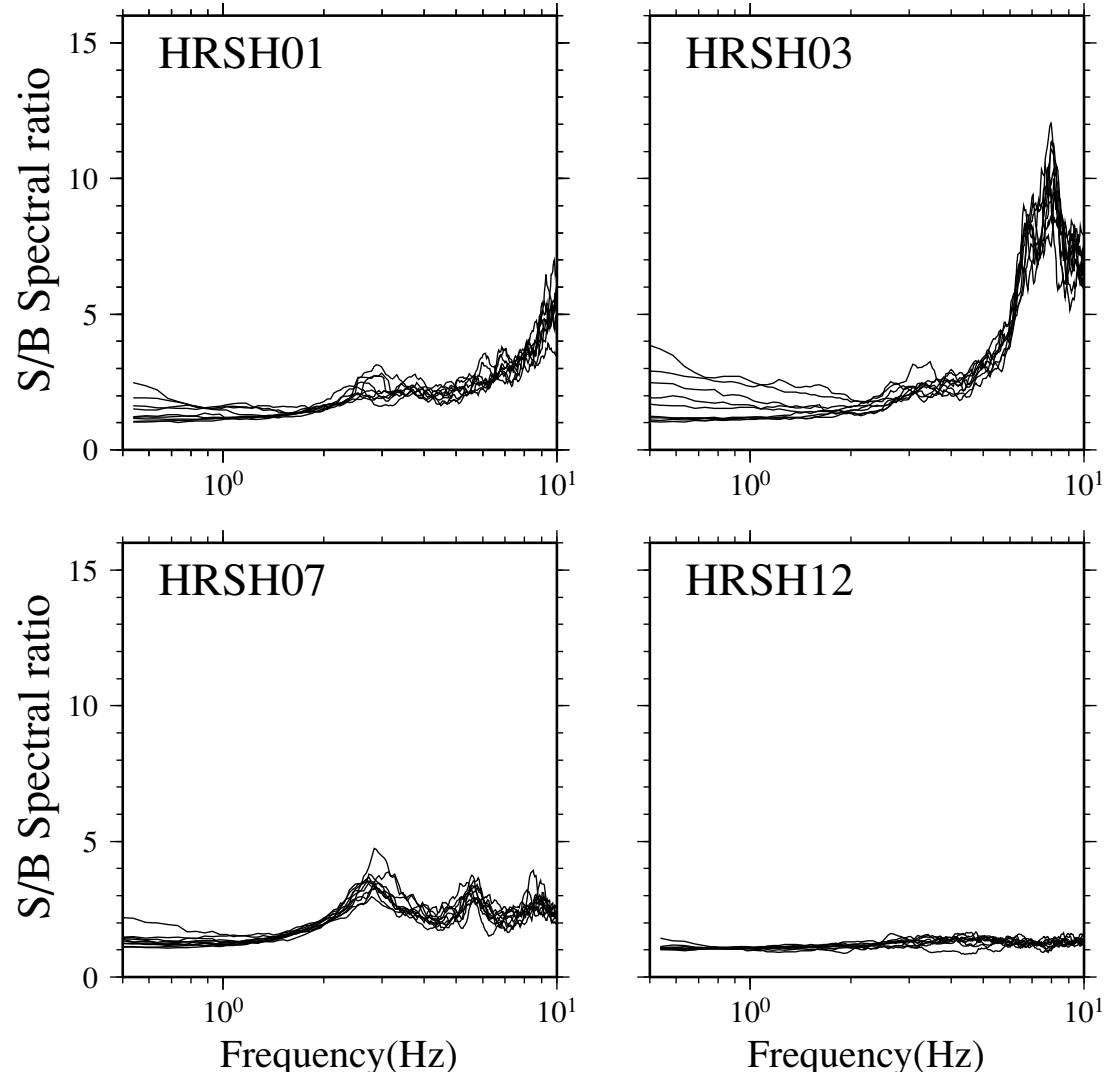

Fig. 6. Spectral ratios of $S$-coda waves using horizontal velocity data observed on the ground surface and those in the borehole of four KiK-net stations.

Table 2. Regression parameters and standard deviations for each station.

\begin{tabular}{crccccc}
\hline Station code & \multicolumn{1}{c}{$b_{1}$} & \multicolumn{1}{c}{$c_{1}$} & $b_{2}$ & $c_{2}$ & $\sigma_{1}$ & $\sigma_{2}$ \\
\hline HRSH01 & 158.182 & -0.718 & 0.019 & 0.580 & 0.174 & 0.203 \\
HRSH02 & 17.590 & -0.379 & 0.023 & 0.573 & 0.153 & 0.189 \\
HRSH03 & 569.361 & -0.846 & 0.007 & 0.785 & 0.239 & 0.181 \\
HRSH04 & 9.843 & -0.392 & 0.014 & 0.671 & 0.095 & 0.121 \\
HRSH05 & 64.809 & -0.519 & 0.002 & 1.012 & 0.180 & 0.155 \\
HRSH06 & 25.406 & -0.296 & 0.038 & 0.458 & 0.156 & 0.210 \\
HRSH07 & 11.850 & -0.232 & 0.023 & 0.631 & 0.094 & 0.188 \\
HRSH08 & 15.861 & -0.455 & 0.006 & 0.876 & 0.107 & 0.173 \\
HRSH09 & 7.523 & -0.308 & 0.007 & 0.858 & 0.111 & 0.179 \\
HRSH10 & 56.512 & -0.423 & 0.009 & 0.745 & 0.184 & 0.170 \\
HRSH11 & 24.917 & -0.502 & 0.008 & 0.789 & 0.120 & 0.173 \\
HRSH12 & 3.020 & -0.145 & 0.007 & 0.817 & 0.062 & 0.162 \\
HRSH13 & 343.302 & -0.834 & 0.008 & 0.759 & 0.195 & 0.151 \\
HRSH14 & 3.935 & -0.147 & 0.007 & 0.800 & 0.147 & 0.196 \\
HRSH15 & 30.861 & -0.520 & 0.011 & 0.696 & 0.167 & 0.198 \\
HRSH16 & 26.890 & -0.439 & 0.006 & 0.865 & 0.154 & 0.152 \\
HRSH17 & 6.295 & -0.283 & 0.009 & 0.758 & 0.131 & 0.204 \\
HRSH18 & 100.635 & -0.668 & 0.004 & 0.904 & 0.152 & 0.143 \\
\hline
\end{tabular}

izontal velocity data on the ground surface and in the borehole, $H_{s}(f) / H_{b}(f)$ as

$$
\frac{H_{s}(f)}{H_{b}(f)}=\frac{\sqrt{P(f)_{\mathrm{NS} 2}+P(f)_{\mathrm{EW} 2}}}{\sqrt{P(f)_{\mathrm{NS} 1}+P(f)_{\mathrm{EW} 1}}},
$$

where $P(f)$ denotes the power spectrum of each component. As a result, the ratios are nearly 1 in the lower frequency domain $(<1 \mathrm{~Hz})$ at the $18 \mathrm{KiK}$-net stations, while the ratios exceed 1 in the higher frequency domain $(\geq 1 \mathrm{~Hz})$ at many stations in Hiroshima prefecture. Figure 6 shows some of the characteristic spectral ratios of $H_{s}(f) / H_{b}(f)$ at stations HRSH01, HRSH03, HRSH07 and HRSH12, respectively. For those stations which show large amplification (HRSH01 and HRSH03), their peaks are found in a higher-frequency band (greater than $3 \mathrm{~Hz}$ ) in contrast to stations which show small amplification (HRSH07 and 
HRSH12). As the seismic intensity was determined to be in the frequency domain from about 0.5 to $10.0 \mathrm{~Hz}$, the response of subsurface structure is significant in the intensity estimation.

\section{Empirical Relation of Amplification for Site- effective Seismic Intensity Estimation}

4.1 Regression analysis for amplification characteristics

As stated above, the amplification ratios $V_{\text {surf }} / V_{\text {bor }}$ tend to decrease gradually with hypocentral distance. We approximate the ratios of $V_{\text {surf }} / V_{\text {bor }}$ as a function of hypocentral distance

$$
V_{\text {surf }}(X) / V_{\text {bor }}(X) \cong R_{1}(X)=b_{1} X^{c_{1}},
$$

where $X$ is the hypocentral distance, and parameters $b_{1}$ and $c_{1}$ are constant. The constants $b_{1}$ and $c_{1}$ are determined using regression analysis. After applying logarithms to both sides of the equation, we obtain

$$
\log R_{1}(X)=\log b_{1}+C_{1} \log X .
$$

For simplicity, we rewrite this equation as follows,

$$
Y=B_{1}+c_{1} X^{\prime}
$$

where we determine $B_{1}$ and $c_{1}$ using the least squares approximation. The parameters determined and the standard deviations $\left( \pm \sigma_{1}\right)$ are listed in Table 2 . The fitted lines (solid lines) with standard deviation of $\sigma_{1}$ (indicated by dashed lines) are plotted for the individual stations in Fig. 5. In general, the derived line represents the distribution of the amplification ratios well, especially for stations HRSH04, HRSH07, HRSH08, HRSH09, HRSH11, HRSH12, HRSH16 and HRSH18. Most of the ratios $V_{\text {surf }} / V_{\text {bor }}$ fall within the calculated standard deviation.

\subsection{Comparison between observed and estimated in- tensities}

Conventionally, the seismic intensity $I$ on the JMA scale is calculated using the empirical relationship as a function of $V_{\text {surf }}(\mathrm{cm} / \mathrm{sec})$ (Midorikawa et al., 1999),

$$
I=2.54+1.82 \log V_{\text {surf }},
$$

where $I$ ranges between 0 and 7 . As stated above, $V_{\text {surf }}$ is estimated using the attenuation relationship and a coefficient $R$ which describes the amplification relative to the bedrock (see Eqs. (1), (2) and (9)). In Fig. 7, the open squares show residuals between the observed and estimated seismic intensities using the conventional method at each of the stations. If the estimated values are underestimated, the residuals become positive. It is clearly seen that most of the residuals deviated from the zero lines. For example, the estimated values at stations HRSH03 and HRSH05 tend to be underestimated, while those at stations HRSH02, HRSH04 and HRSH09 tend to be overestimated. There are especially large differences between the observed and estimated intensities at HRSH01, HRSH03 and HRSH04. As the coefficient $R$ is derived to give an averaged estimation of $V_{\text {surf }}$ nationwide without accounting for the propagation path effects, the differences may be due to the definition of this parameter. The amplification coefficient $R$ shall be described as a function of distance. Moreover, as the attenuation relationship of Midorikawa and Ohtake (2003) is derived using strong motion data within $300 \mathrm{~km}$ of the epicenters, the estimation of $V_{\text {surf }}$ at a distance further than $300 \mathrm{~km}$ may not be accurate. However, the attenuation relationship is sometimes adopted to check the attenuation of ground motions at distances of over $300 \mathrm{~km}$ (e.g. NIED on-line report), so that we assume that it is applicable to events at distances greater than $300 \mathrm{~km}$ without leading to notable errors in the analysis. Thus, we derive amplification formulas as a function of distance at individual stations.

The revised estimation procedure is illustrated in Fig. 8. First, the peak velocities $V_{\text {bed }}(\mathrm{cm} / \mathrm{s})$ on the engineering bedrock site are estimated using the attenuation relationship of Midorikawa and Ohtake (2003) for each event. Second, we correct $V_{\text {bed }}$ to the peak velocities $V_{\text {bor }}(\mathrm{cm} / \mathrm{s})$ at the borehole site. The ratios $V_{\text {bor }} / V_{\text {bed }}$ gradually become close to 1 with hypocentral distance (Fig. 9) and is described in the same way as in Eq. (11),

$$
V_{\text {bor }}(X) / V_{\text {bed }}(X) \cong R_{2}(X)=b_{2} X^{c_{2}},
$$

where parameters $b_{2}$ and $c_{2}$ are constant (curve fittings are plotted in Fig. 9 and the parameters are listed in Table 2 for all the stations). Accordingly, we estimate the peak velocities of the borehole stations as

$$
V_{\text {bor }}=R_{2}(X) \times V_{\text {bed }}
$$

and determine $V_{\text {surf }}$ using the amplification function derived above as

$$
V_{\text {surf }}=R_{1}(X) \times V_{\text {bor }} \text {. }
$$

Equations (16) and (17) can be combined to make a relation between $V_{\text {bed }}$ and $V_{\text {surf }}$ as follows:

$$
V_{\text {surf }}=R_{1}(X) \times R_{2}(X) \times V_{\text {bed }}
$$

(Compare the ratios $V_{\text {surf }} / V_{\text {bed }}$ derived from the use of a conventional $R$ (Eq. (9), dashed lines) and those derived in this study (Eq. (18), solid lines) in Fig. A1.) Finally, we estimate intensities on the ground surface using the Eq. (14).

In Fig. 7 the residuals between the observed and estimated intensities (plotted with solid black squares) tend to converge to zero better than the residuals (open squares) using the conventional method. Most of the root-meansquares (RMS's) fall within 0.5 (except at HRSH01 and HRSH03). This improvement is effective for the stations which show large surface amplification.

\section{Discussion}

\subsection{Characteristics of site amplification in the far-field event recordings}

The amplification $V_{\text {surf }} / V_{\text {bor }}$ is affected by the coupling of seismic waves with the heterogeneous structure through the propagation paths. In Hiroshima prefecture, the natural frequencies of subsurface structure at each of the KiK-net stations are over $1 \mathrm{~Hz}$. Therefore, the high-frequency components of the incident waves affect the estimation of intensities. For most stations, residuals between the estimated and observed intensities in Fig. 7 are large at greater distances. For the intermediate-depth events which occurred 


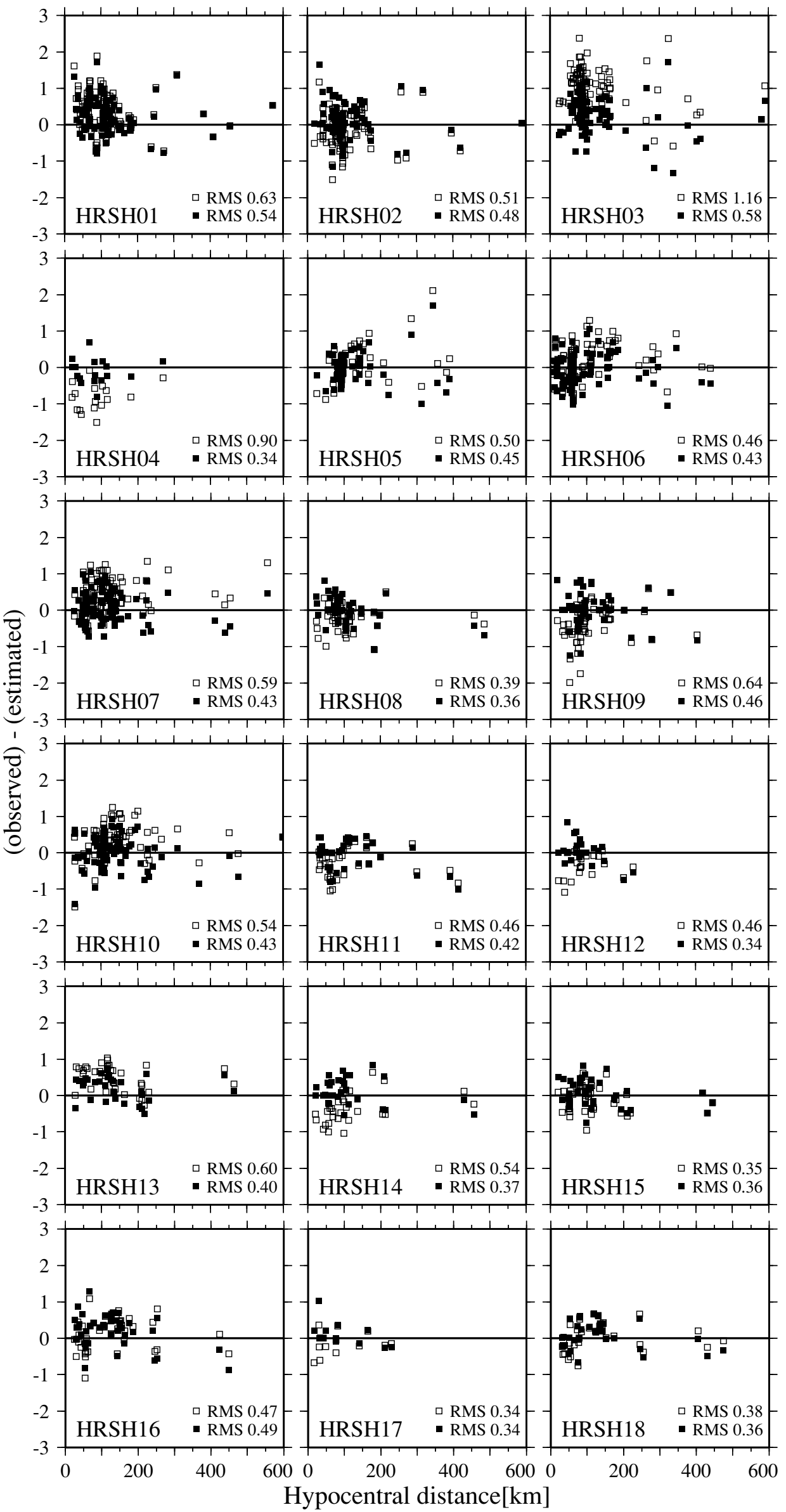

Fig. 7. Residuals between observed and estimated seismic intensities at $18 \mathrm{KiK}$-net stations. Residuals derived using a conventional method (Midorikawa and Ohtake, 2003; open squares) and our method (filled squares) are compared. 


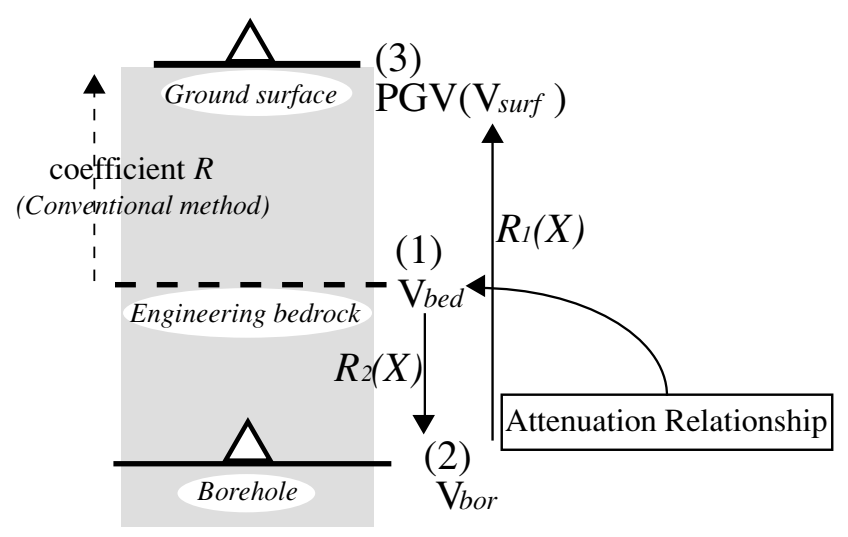

Fig. 8. Concept of seismic intensity estimates using our calibration for data at KiK-net stations. This procedure consists of three stages: (1) estimation of peak velocity on the engineering bedrock site $V_{\text {bed }}$ using the attenuation relationship of Midorikawa and Ohtake (2003); (2) correction of $V_{\text {bed }}$ to the peak velocity on the borehole site $V_{\text {bor }}$ using the empirical relationship; (3) determination of $V_{\text {surf }}$ and seismic intensity on the ground surface using the empirical amplification relationship.

within the subducting Philippine Sea plate (Events 1 and 4 in Fig. 3 and Table 3$), V_{\text {surf }} / V_{\text {bor }}$ are larger than the estimated values and the seismic intensities tend to be underestimated (in Fig. 5), while $V_{\text {surf }} / V_{\text {bor }}$ are small and the estimated intensities tend to be overestimated for the shallow events (Events 2 and 3 in Figs. 3 and 5 and Table 3). Moreover, the ratios $V_{\text {surf }} / V_{\text {bor }}$ of the two stations (HRSH01 and HRSH03) for the specific events (see the colored squares) show characteristic amplification in Fig. 10. These two stations are located close to each other $(\sim 19 \mathrm{~km})$. The ratios $V_{\text {surf }} / V_{\text {bor }}$ of the specific events were found to show a tendency similar to that of the seismic waves propagated through similar heterogeneous structures. This observation suggests that calibrations at individual stations are necessary to account for 3D structural effects. The large residuals are interpreted as follows: (1) high-frequency guided waves traveling from intermediate-depth events in the subducting Philippine Sea plate result in large amplifications at a further distance; (2) for shallow events, high-frequency waves are largely scattered and attenuated before the waves reach individual sites (see Appendix B). Morikawa et al. (2006) recently proposed an empirical attenuation relationship that accounts for the effects of propagation paths in the region of abnormal intensity distribution. It is desirable that the additional corrections for the calibration be considered when accounting for the propagation path effects.

\subsection{Characteristics of site amplification in the near- field event recordings}

On the other hand, for several near-field events, the residuals between the estimated and observed intensities are also large (see Fig. 7). As our intention was to predict near-field strong motions as accurately as possible, we explored ways to reduce large residuals accounting for propagation path effects. The nonlinear effects of soil response should also be considered for stations located in a near-fault region.

In Hiroshima prefecture, strong ground motions were recorded during the 2000 Western Tottori earthquake $\left(M_{\mathrm{W}} 6.8\right)$ and the 2001 Geiyo earthquake $\left(M_{\mathrm{W}} 6.7\right)$. The characteristic amplifications were seen in the recordings of the KiK-net stations located in the southern part of Hiroshima prefecture (Kanno and Miura, 2006). We calculated the spectral ratios of the coda portion of the $S$ waves using horizontal velocity seismograms recorded on the ground surface and in the borehole for the two earthquakes sequences (see Eq. (10)). In Fig. 11, the thick lines denote the spectral ratios which were derived from the data of mainshocks of the 2000 Western Tottori earthquake and the 2001 Geiyo earthquake (gray and black, respectively), and the thin lines denote those of the aftershocks. In this figure we can clearly see that the peak spectral ratios of the mainshocks have shifted to the lower frequency band, while the shapes of the spectra are similar to each other in the recordings of the aftershocks.

Since the amplification $V_{\text {surf }} / V_{\text {bor }}$ in the region of interest is explained by the interactions of high-frequency spectral components between the propagating waves and the soil, the ratios $V_{\text {surf }} / V_{\text {bor }}$ of these mainshocks are smaller than the values estimated from the regression line (see the open squares in Fig. 10). Accordingly, the estimated intensities (on the ground surface) at these stations could be overestimated although not all the stations located close to an epicenter show such nonlinear amplification (Seed and Idriss, 1970).

Midorikawa and Ohtake (2003) pointed out that the estimated amplitudes on the ground surface are variable in their empirical attenuation relationship because of the effect of focal mechanisms as well as propagation paths and subsurface structures. The ground motion amplitudes in a high-frequency band have been reported to show variation with $M_{\mathrm{W}}$ (Dan et al., 2001) because the amplitude level in a high-frequency band may be controlled by the effective stress at the hypocenter. The relation between the stress drop and $M_{\mathrm{W}}$ may also be variable for small events because of the dependency of stress drop on $M_{\mathrm{W}}$ (Youngs et al., 1995). Furthermore, the effects of fault rupture directivity and radiation pattern are responsible for the ground motions near the epicentral region (Koyama, 1987; Somerville et al., 1997). The effect of radiation pattern appears particularly evident in a case of small events (Midorikawa and Ohtake, 2003). Since the data used in this study contain a lot of small events, such effects may have contributed to our calibration.

\subsection{Revised estimation of seismic intensity considering directional dependence}

We have attempted to improve the estimation of the intensities at stations HRSH01 and HRSH03 where the residuals (RMS's) were over 0.5 considering some selected events. The ratios $V_{\text {surf }} / V_{\text {bor }}$ and $V_{\text {bor }} / V_{\text {bed }}$ calculated from the record of these events show large deviations from the regression lines (see the colored symbols in Fig. 10(a) and Fig. 10(b)). The events which occurred in the source regions $\mathrm{A}$ through $\mathrm{J}$ in Fig. 3 are denoted in different colors. We can see that the abnormal ratios $V_{\text {bor }} / V_{\text {bed }}$ and $V_{\text {surf }} / V_{\text {bor }}$ vary according to the regions. Furthermore, we can see that the plots of $V_{\text {surf }} / V_{\text {bor }}$ for some events (see the navy, light blue, green and yellow squares) are smaller than the regression line, whereas the plots of $V_{\text {bor }} / V_{\text {bed }}$ for the corresponding events are considerably larger than the regression line. Thus, it is appropriate to analyze these two amplitude ratios 


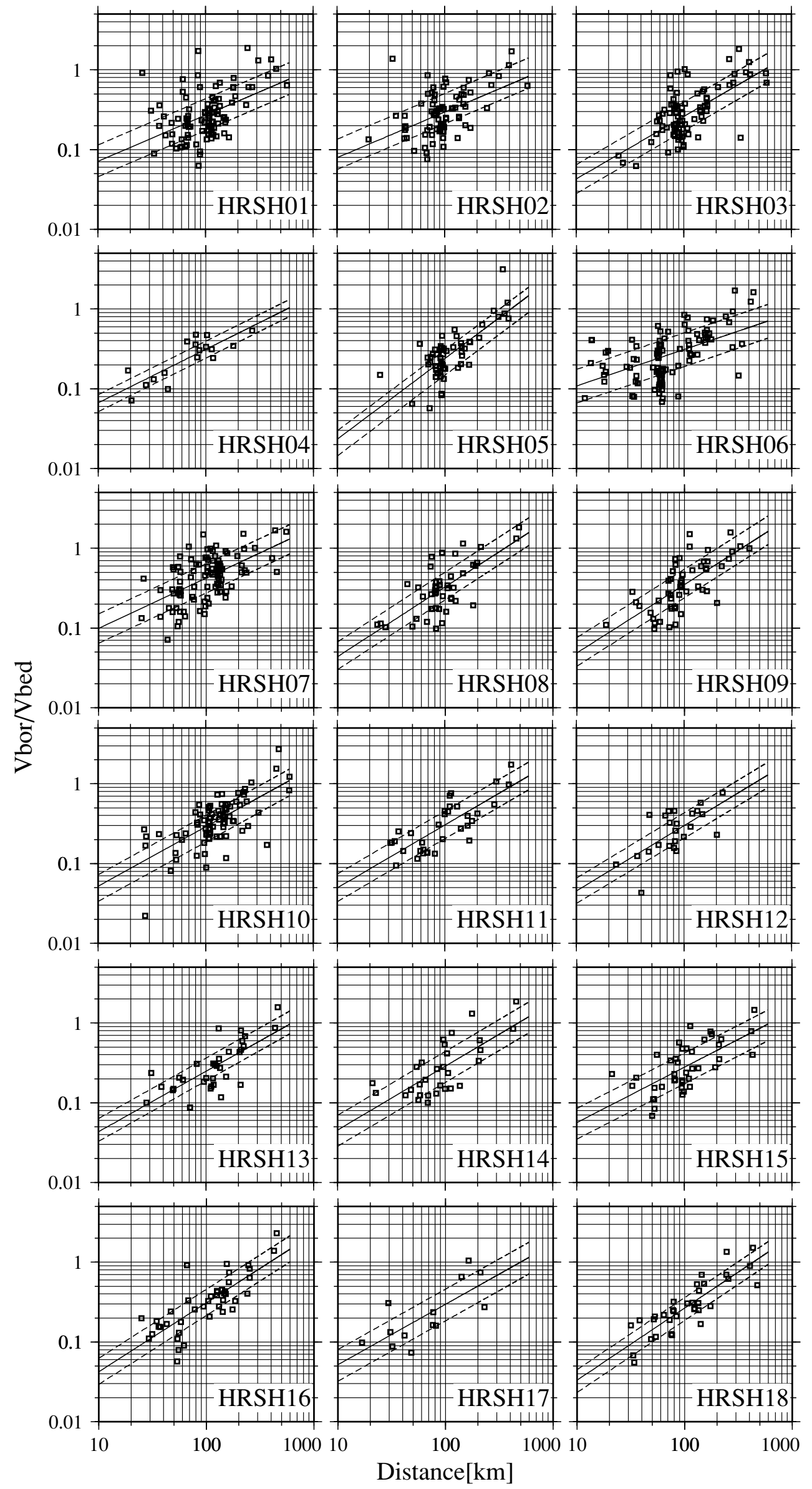

Fig. 9. Ratios of the peak velocity amplitudes in the borehole to the estimated peak amplitudes on the engineering bedrock ( $\left.V_{\text {bor }} / V_{\text {bed }}\right)$ as a function of hypocentral distance. Regression fitted lines and $\pm \sigma_{2}$ for each station (dashed lines) are also plotted. 
Table 3. List of the source parameters of the selected events in Fig. 3.

\begin{tabular}{|c|c|c|c|c|c|}
\hline Event & $\begin{array}{c}\text { Origin time (JST) } \\
\text { (yy/mm/dd hh:mm:ss) }\end{array}$ & $\begin{array}{l}\text { Depth } \\
(\mathrm{km})\end{array}$ & $M_{\mathrm{W}}$ & $\begin{array}{l}\Delta 1^{*} \\
(\mathrm{~km})\end{array}$ & $\begin{array}{l}\Delta 2 * * \\
(\mathrm{~km})\end{array}$ \\
\hline 1 & $2000 / 04 / 02$ 21:25:33 & 146.9 & 4.8 & 271.1 & 290.0 \\
\hline 2 & 2002/11/04 13:36:00 & 35.2 & 5.7 & 242.3 & 261.3 \\
\hline 3 & 2005/03/20 10:53:40 & 9.2 & 6.6 & 272.2 & 286.5 \\
\hline 4 & 2006/06/12 05:01:24 & 146.2 & 6.4 & 203.1 & 221.7 \\
\hline
\end{tabular}

*Hypocentral distance to HRSH01.

**Hypocentral distance to HRSH03.

(a)
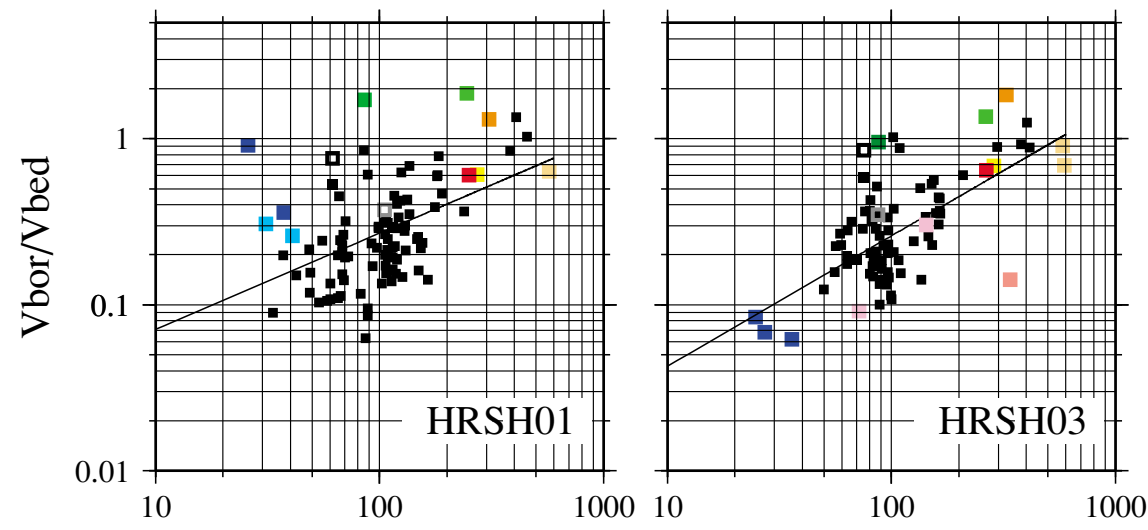

(b)
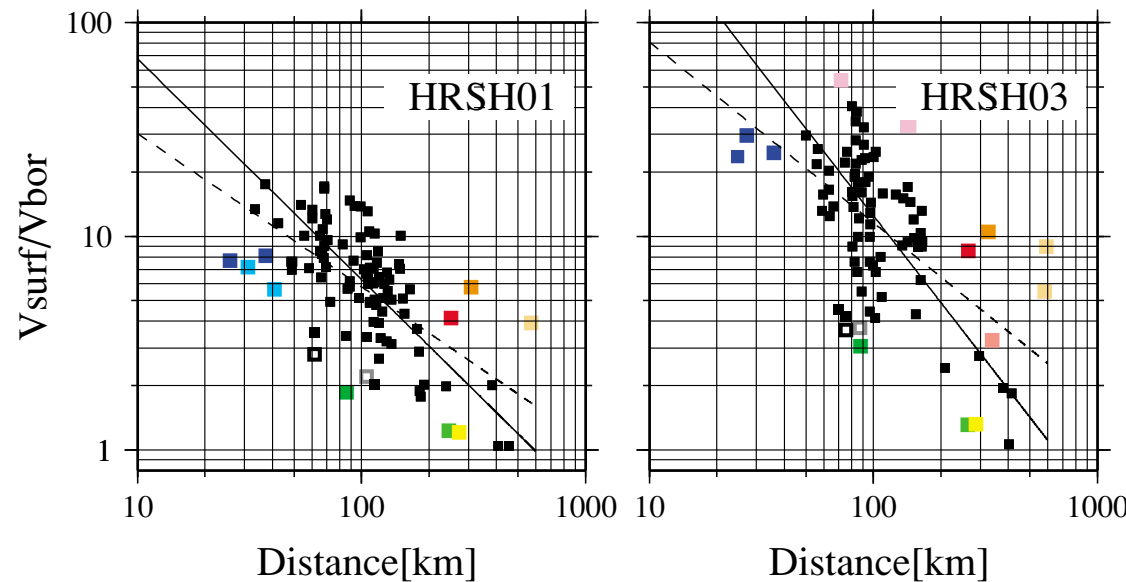

Distance $[\mathrm{km}]$

Distance[km]
$\because \mathrm{A} \backsim \mathrm{B} \backsim \mathrm{C} \backsim \mathrm{D}$
E $\square \mathrm{F}$
$\square \mathrm{G} \quad \mathrm{H}$
$\mathrm{H} \square \mathrm{I} \square \mathrm{J}$
口 2000 Western Tottori Earthquake a2001 Geiyo Earthquake

Fig. 10. (a) Regression lines of $V_{\text {bor }} / V_{\text {bed }}$ for stations HRSH01 and HRSH03 (regression parameters are the same as in Fig. 9). The events which occurred in the source regions A through $\mathrm{J}$ in Fig. 3 are also distinguished by colors. (b) Revised regression lines of $V_{\text {surf }} / V_{\text {bor }}$ (solid lines) for the stations HRSH01 and HRSH03. The events which occurred in the source regions A through J in Fig. 3 are denoted by different colors. Re-calculated regression parameters are listed in Table 3 .

separately and attempt to investigate the causes of the difference. We then calculated the regression line excluding these events (solid lines in Fig. 10(b)) as

$$
V_{\text {surf }}(X) / V_{\text {bor }}(X) \cong R_{1^{\prime}}(X)=b_{1^{\prime}} X^{c_{1^{\prime}}} .
$$

The calculated regression parameters $\left(b_{1^{\prime}}, c_{2^{\prime}}\right)$ are listed in Table 4, and the intensities estimated from $V_{\text {surf }}$ 's thus calculated are plotted in Fig. 12. The intensity estimation has been improved substantially (i.e. large reduction of residuals). The RMS's between the estimated and observed intensities are within 0.5 after the removal of the specific events. This indicates that our approach of amplification calibration provides a more accurate estimation of intensities on the ground surface. 

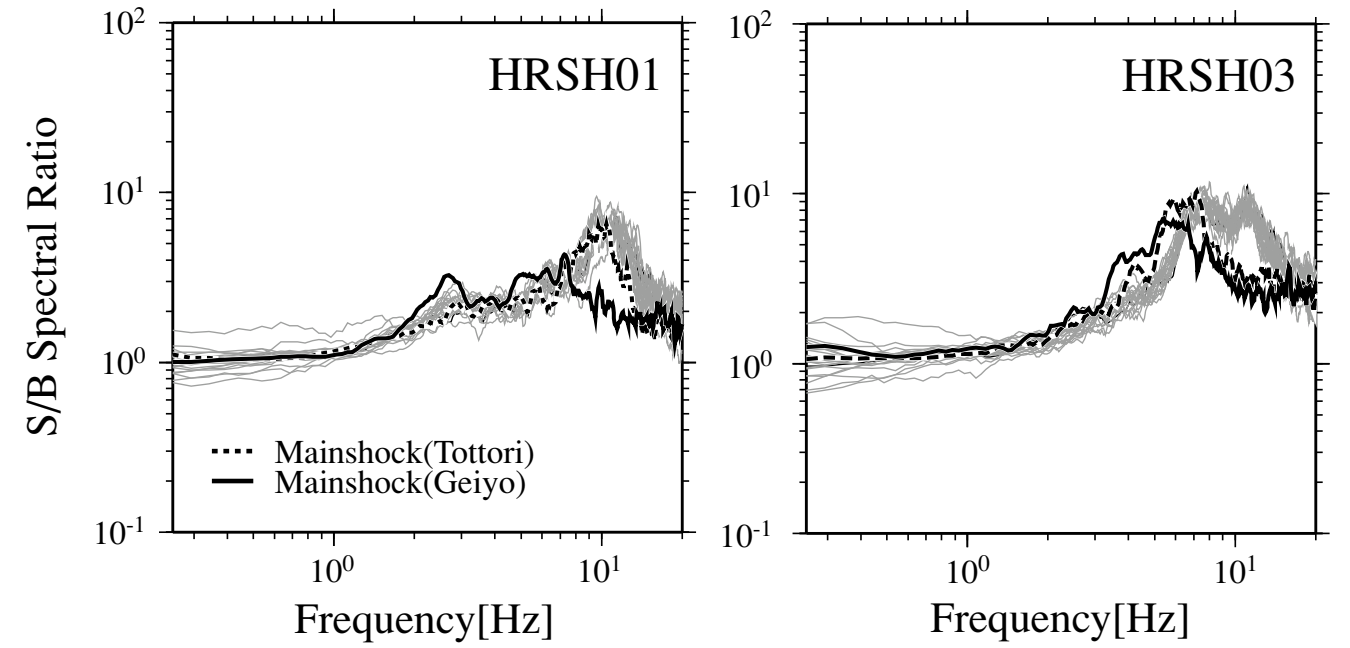

Fig. 11. Spectral ratios of $S$-coda waves using horizontal velocity data observed on the ground surface and those in the borehole of KiK-net stations (HRSH01 and HRSH03) for the 2000 Western Tottori earthquake (thick solid line), the 2001 Geiyo earthquake (thick dotted line) and the aftershocks (thin lines).
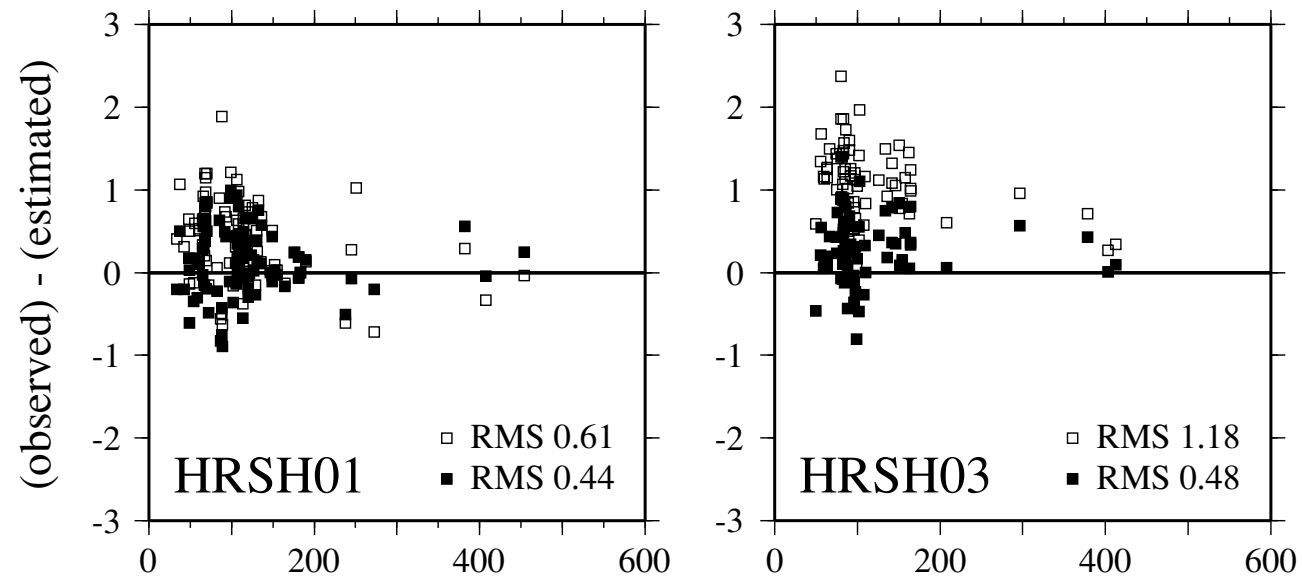

Hypocentral distance $[\mathrm{km}]$

Hypocentral distance $[\mathrm{km}]$

Fig. 12. Residuals between observed and estimated (with calibration) seismic intensities at two KiK-net stations. Here the specific events which show characteristic amplification because of the incident directions are excluded in the regression analysis. Residuals derived using conventional method (open squares) and our method (filled squares) are plotted.

Table 4. Re-calculated regression parameters and standard deviations for the two stations.

\begin{tabular}{crcc}
\hline Station code & \multicolumn{1}{c}{$b_{1^{\prime}}$} & $c_{1^{\prime}}$ & $\sigma_{3}$ \\
\hline HRSH01 & 729.508 & -1.033 & 0.141 \\
HRSH03 & 6285.590 & -1.351 & 0.195 \\
\hline
\end{tabular}

\section{Conclusions}

We investigated amplification factors between the borehole and the ground surface by calculating the ratios of $V_{\text {surf }} / V_{\text {bor }}$-i.e. surface amplification-at $18 \mathrm{KiK}$-net stations in Hiroshima prefecture. Results show that: (1) the surface amplifications $V_{\text {surf }} / V_{\text {bor }}$ generally decrease with hypocentral distance; (2) the range of the ratios varies among the stations with the maximum value exceeding 50 at HRSH03; (3) the ratios $V_{\text {surf }} / V_{\text {bed }}$ shall be described as a function of hypocentral distance instead of the convention- ally used constant $R$; (4) the seismic intensities estimated from the use of the newly derived formula show substantial improvement in the accuracy for most stations. Moreover, after we considered the amplification dependence on the incident direction, the estimated intensities showed reasonable improvement. This calibration of amplification factors would help construct a real-time information system such as REIS to provide more accurate intensity estimates on the ground surface at given sites.

Acknowledgments. We used ground motion data from the KiKnet provided by National Research Institute for Earth Science and Disaster Prevention (NIED). We also used the hypocentral information and data of seismic intensities by Japan Meteorological Agency (JMA). We express our appreciation to these organizations for providing useful data and information. We also thank Shigeki Horiuchi at NIED for useful discussions, and Takashi Iidaka, Editor and two anonymous reviewers for many constructive comments. Figures were plotted using Generic Mapping Tools (Wassel and Smith, 1995). 

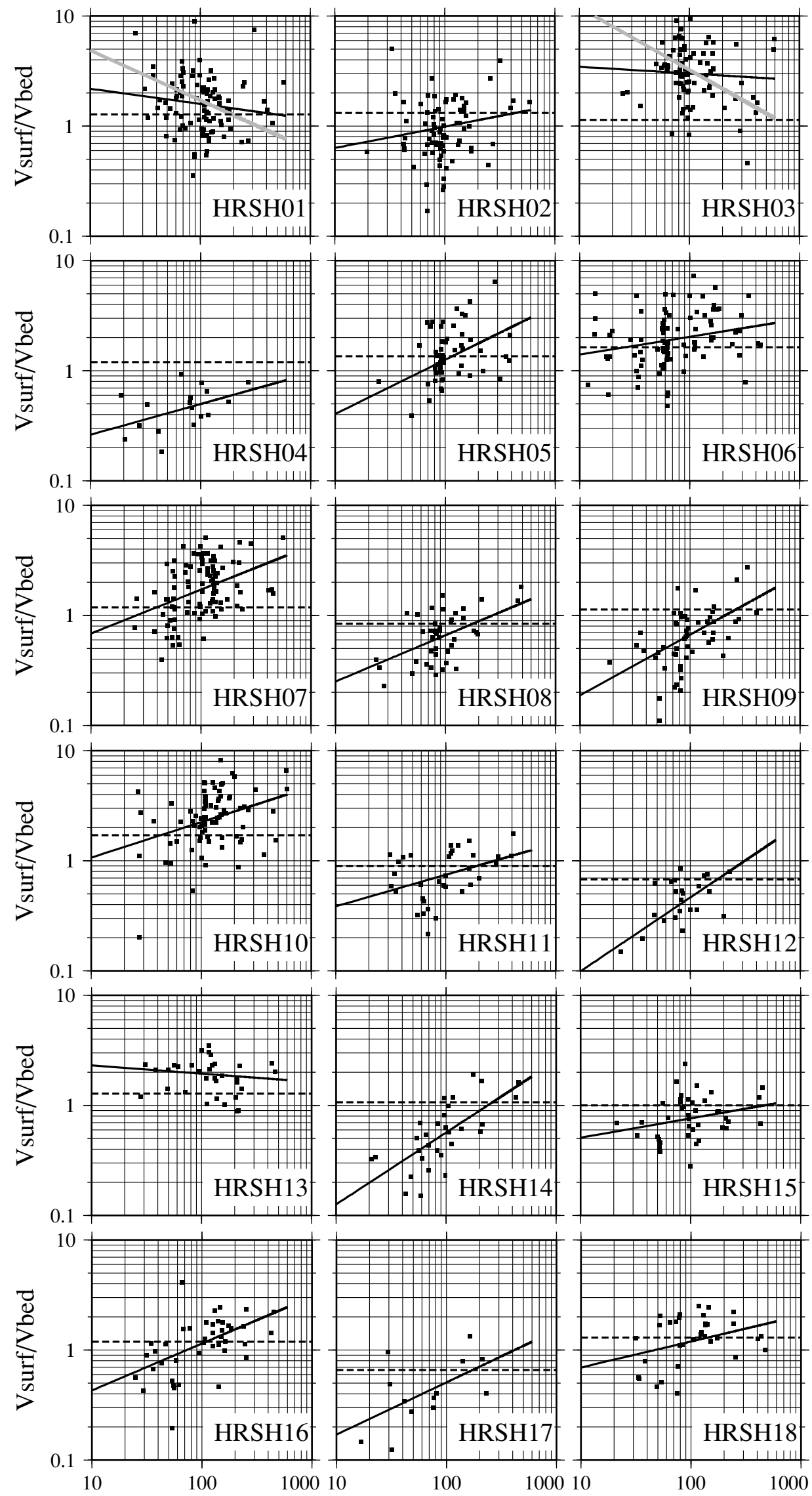

Hypocentral distance[km]

Fig. A1. Ratios of the peak velocity amplitudes on the ground surface to the estimated peak amplitudes on the engineering bedrock ( $\left.V_{\text {surf }} / V_{\text {bed }}\right)$ as a function of hypocentral distance. The regression fitted lines derived in Eq. (18) (thick lines) and the conventional amplification coefficient $R$ (dotted lines) are also plotted. The revised regression lines derived using the revised functions of $V_{\text {surf }} / V_{\text {bor }}$ for stations HRSH01 and HRSH03 (see Fig. 10) are also plotted (thick gray lines). 
(a)HRSH01

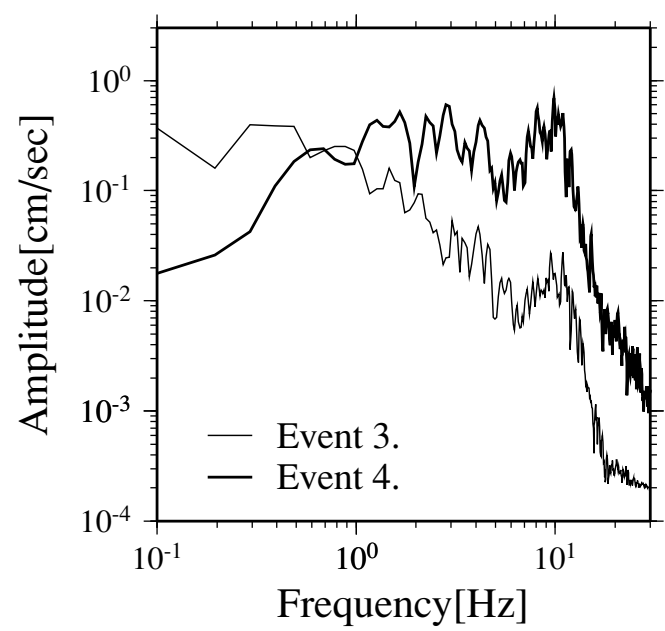

(b)HRSH03

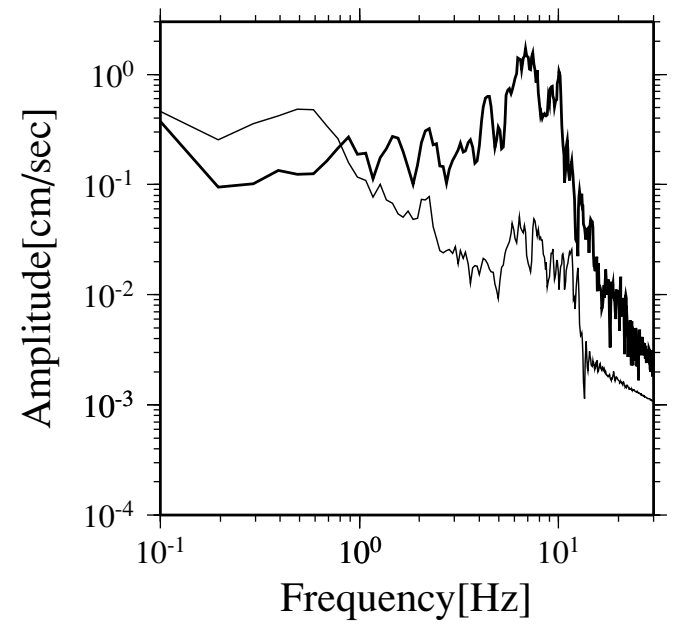

Fig. A2. Fourier spectra of seismograms recorded for Events 3 and 4 (see Fig. 3 and Table 3 ) on the ground surface at stations HRSH01 and HRSH03.

\section{Appendix A. Ratios between $V_{\text {surf }}$ and $V_{\text {bed }}$}

In this study, we carried out three steps of calibration (see Fig. 8 in the main text). We examined the amplification factors between the borehole and the ground surface $\left(R_{1}(X)\right)$, and those between the bedrock and the borehole $\left(R_{2}(X)\right)$ individually. This calibration revealed that $R_{1}(X)$ and $R_{2}(X)$ show variation among events. We then analyzed these two amplitude ratios separately in an attempt to investigate the causes of the difference. The calibration based on a single relation between $V_{\text {bed }}$ and $V_{\text {surf }}$ may be applicable to an arbitrary site which has no borehole station. In Fig. A1, we plotted $V_{\text {surf }} / V_{\text {bed }}$ for each of the KiK-net stations and the regression lines (black lines) which are derived using Eq. (18). The gray lines at stations HRSH01 and HRSH03 denote the revised regression line of $V_{\text {surf }} / V_{\text {bed }}$, which are derived using Eq. (19). For comparison, we also plotted $R$, which are derived conventionally (see Eq. (9)). The distance dependence of $V_{\text {surf }} / V_{\text {bed }}$ is observed (although the plots largely scatter at HRSH01, HRSH02, HRSH03, HRSH06 and HRSH10).

\section{Appendix B. Fourier spectra of specific event records}

In Fig. A2 we plotted Fourier spectra of the $S$-coda waves (transverse components) for Events 3 (the 2005 West off Fukuoka, depth $=9 \mathrm{~km}$ ) and 4 (the 2006 Mid Oita, depth $=146 \mathrm{~km}$ ) (see Fig. 3 and Table 4) which show anomalous amplification at stations HRSH01 and HRSH03 on the ground surface. These events have similar magnitudes $\left(M_{\mathrm{W}} \sim 6.6\right)$ and are located to in the Kyushu region (see Table 4). We can see that the spectra are largely amplified in a high-frequency band for Event 4 in comparison with the spectra of Event 3. As stated in the Discussion, this illustrates that the high-frequency components of the incident waves mainly affect the amplification $V_{\text {surf }} / V_{\text {bed }}$ and are critical in the accurate estimation of intensity.

\section{References}

Aoi, S., K. Obara, S. Hori, K. Kasahara, and Y. Okada, New Japanese uphole/downhole strong-motion observation network: KiK-net, Seism. Res. Lett., 72, 239, 2000.

Dan, K., M. Watanabe, T. Sato, and T. Ishii, Short period source spectra inferred from variable slip rupture models and modeling of earthquake faults for strong motion prediction by semi empirical method, J. Struct. Eng., AIJ, 545, 51-62, 2001 (in Japanese with English abstract).

Fukushima, Y. and T. Tanaka, A new attenuation relation for peak horizontal acceleration of strong earthquake ground motion in Japan, Bull. Seism. Soc. Am., 80, 757-783, 1990.

Fukuyama, E., M. Ishida, D. S. Dreger, and H. Kawai, Automated seismic moment tensor determination by using on-line broadband seismic waveforms, Zisin (J. Seism. Soc. Japan), 51, 149-156, 1998 (in Japanese with English abstract).

Hanks, T. C. and H. Kanamori, A moment magnitude scale, J. Geophys. Res., 84, 2348-2350, 1979.

Horiuchi, S., H. Negishi, K. Abe, A. Kamimura, and Y. Fujinawa, An automatic processing system for broadcasting earthquake alarms, Bull. Seism. Soc. Am., 95, 708-718, 2005.

Japan Meteorological Agency, On Seismic Intensity, 238 pp, Gyosei, Tokyo, 1996 (in Japanese).

Kanamori, H., The energy release in great earthquakes, J. Geophys. Res., 82, 2981-2987, 1977.

Kanno, T. and K. Miura, Evaluation of site effects during the 2001 Geiyo earthquake in Hiroshima prefecture, J. Struct. Eng., AIJ, 597, 151-157, 2006 (in Japanese with English abstract).

Kanno, T., A. Narita, N. Morikawa, H. Fujiwara, and Y. Fukushima, A New Attenuation Relation for Strong Ground Motion in Japan Based on Recorded Data, Bull. Seism. Soc. Am., 96, 879-897, 2006.

Koyama, J., Short period seismic directivity, Zisin (J. Seism. Soc. Japan), 40, 397-404, 1987 (in Japanese with English abstract).

Matsusaki, S., Y. Hisada, and Y. Fukushima, Attenuation relation of JMA intensity applicable to near source region, J. Struct. Eng., AIJ, 604, 201208, 2006 (in Japanese with English abstract).

Midorikawa, S. and Y. Ohtake, Empirical analysis of variance of ground motion intensity in attenuation relationships, J. Japan Assoc. Earthq. Eng., 3, 59-70, 2003 (in Japanese with English abstract).

Midorikawa, S., M. Matsuoka, and K. Sakugawa, Site effects on strongground motion records during the 1987 Chiba-ken-toho-oki, Japan earthquake, The 9th Japan Earthquake Engineering Symposium, 3, 8590, 1994.

Midorikawa, S., K. Fujimoto, and I. Muramatsu, Correlation of New J.M.A. instrumental seismic intensity with former J.M.A. seismic intensity and ground motion parameters, J. Soc. Safe. Science, 1, 51-56, 1999 (in Japanese with English abstract).

Morikawa, N., T. Kanno, A. Narita, H. Fujiwara, and Y. Fukushima, New additional correction terms for attenuation relations of peak amplitudes and response spectra corresponding to the anomalous seismic intensity in northeastern Japan, J. Jpn Assoc. Earthq. Eng., 6, 23-41, 2006 (in Japanese with English abstract).

Obara, K., Hi-net: High-sensitivity seismograph network, Japan, in Methods and Applications of Signal Processing in Seismic Network Operations, edited by T. Takanami and G. Kitagawa, 266 pp, Springer, Berlin, 2002 . 
Seed, H. B. and I. M. Idriss, Soli moduli and damping factors for dynamic response analyses, Report No. EERC70-10, EERC, Univ. of California, Berkeley, 1970.

Shiomi, K., K. Obara, S. Aoi, and K. Kasahara, Estimation on the azimuth of the Hi-net borehole seismometers, Zisin (J. Seism. Soc. Japan), 56, 99-110, 2003 (in Japanese with English abstract).

$\mathrm{Si}, \mathrm{H}$. and S. Midorikawa, New attenuation relationships for peak ground acceleration and velocity considering effects of fault type and site condition, J. Struct. Constr. Eng., 523, 63-70, 1999 (in Japanese with English abstract).

Somerville, P. G., N. F. Smith, R. W. Graves, and N. A. Abrahamson, Modification of empirical strong motion attenuation relations to include the amplitude and duration effects of rupture directivity, Seism. Res. Lett., 68, 199-222, 1997.

Takahashi, T., A. Asano, H. Okada, T. Saiki, K. Irikura, J. X. Zhao, J. Zhang, H. K. Thio, P. G. Somerville, Ya. Fukushima, and Yo. Fukushima, Attenuation relations of strong ground motion in Japan using site classification based on predominant period, CSNI Workshop, 2004.
Takemura, M., Magnitude-seismic moment relations for the shallow earthquakes in and around Japan, Zisin (J. Seism. Soc. Japan), 43, 257-265, 1990 (in Japanese with English abstract).

Wessel, P. and W. H. F. Smith, New version of the genetic mapping tools released, EOS Trans. Am. Geophys. Un., 76, 329, 1995.

Yamamoto, S. and S. Horiuchi, Effectiveness of shaking intensity magnitude for realtime intensity estimation in early warning system, Abstracts 2005 Japan Earth Planet. Sci. Joint Meeting, S046-004, 2005.

Yamamoto, S., S. Horiuchi, H. Negishi, and T. Urabe, Broadcasting and receiving system for earthquake early warning using DVB satellite communication, Zisin (J. Seism. Soc. Japan), 58, 71-76, 2005 (in Japanese with English abstract).

Youngs, R. R., N. Abrahamson, F. I. Mkdisi, and K. Sadigh, Magnitude dependence variance of peak ground acceleration, Bull. Seism. Soc. Am., 85, 1161-1176, 1995.

T. Hayashida (e-mail: hayasida@geol.sci.hiroshima-u.ac.jp) and F. Tajima 